\title{
Neonatal Outcomes of Maternal Alloimmunization to Red Blood Cell Antigens
}

\author{
Jonathan Sgro ${ }^{1}$, Thivia Jegathesan ${ }^{1}$, Douglas Campbell ${ }^{1}$, Katerina Pavenski ${ }^{1}$, and Jillian \\ Baker $^{1}$ \\ ${ }^{1}$ St Michael's Hospital
}

December 31, 2021

\begin{abstract}
We conducted a retrospective chart review of ten years of mother-neonate dyads at our centre with RBC mismatch to describe the type and frequency of maternal red blood cell (RBC) alloantibodies in our centre and newborn outcomes. Half of the 300 mother-neonate pairs had a total of 173 clinically significant maternal RBC alloantibodies. Rh antibodies were the most common, accounting for $67 \%$ (Anti-D accounting 10\%) and thus continue to be the most prevalent clinically significant antibodies detected in maternal patients. Neonates born to women with all types of Rh alloimmunization were shown to require interventions to treat HDFN, including readmission.
\end{abstract}

\section{Introduction}

Red blood cell (RBC) antibodies are detected in less than $1 \%$ of prenatal specimens, yet when present may have important implications for the fetus and newborn ${ }^{1}$ with the most common being Anti- $\mathrm{E}^{2}$. When there is incompatibility between maternal antibodies and fetal antigens of paternal origin, hemolytic disease of the fetus and newborn (HDFN) may occur ${ }^{3}$. The neonates may require treatment for either the anemia or significant hyperbilirubinemia ${ }^{4}$.

Some maternal RBC antibodies do not cause severe effects in a neonate or fetus ${ }^{5}$. It is not known why the presence of maternal antibodies does not correlate with neonatal outcome. Furthermore, the overall prevalence of maternal antibodies and HDFN is not well understood in a healthy pregnant population. The most commonly reported antibodies worldwide causing significant HDFN are those directed against the Rh system ${ }^{1}$. The overall incidence of HDFN is estimated to be 3-80/100 000, depending on the definition ${ }^{6}$.

There is a gap in the literature regarding the effects of maternal antibodies on fetal/neonatal outcomes outside of isohemagglutinins and anti-D antibodies. Therefore, the goal of this study was to determine the incidence and identity of maternal antibodies in a large tertiary care centre and to correlate their presence to neonatal outcomes.

\section{Methods}

\section{Design}

A retrospective review was conducted of all women who underwent prenatal testing at St. Michael's hospital between January 2006 - March 2016. St. Michael's hospital's Research Ethics Board approval was received for the study; individual patient consent was not sought.

All women underwent group and screen testing (Provue, Ortho). Positive antibody screens were investigated to identify RBC alloantibodies. Women with positive antibody screen due to passive anti-D due to RhIG administration were excluded. Women with clinically significant alloantibodies also had the titre of the 
antibody determined serially throughout the pregnancy. Typically, titres were performed every 2-4 weeks until delivery, or until a critical titre is reached (32 for all antibodies except anti- $\mathrm{K}$ as any titre of anti$\mathrm{K}$ is considered critical) ${ }^{7}$. Paternal phenotyping was done when needed. All neonates born to women with clinically significant alloantibodies underwent cord testing including direct antiglobulin test and RBC phenotyping of implicated antigens.

We included all women with a positive antibody screen due to an RBC alloantibody and neonates who were shown to have the antigen on their cord RBC that was cognate to maternal alloantibody. Women with a history of administration of RhIG were excluded as well as mothers with antibodies known to be not clinically significant. Furthermore, we excluded pregnancies who also had co-existent ABO incompatibility as we wanted to be sure that the effects observed would be due to alloantibodies. Neonatal data from women who delivered outside of our hospital were not accessible for analysis.

\section{Data collection}

Data collected included antibody specificities and titres, number of at-risk pregnancies and fetal/neonatal outcomes (including gestational age, birth weight, sex, delivery method, hours of age at peak bilirubin, neonatal hemoglobin, hospital stay and duration of phototherapy, IVIG, RBC transfusion and/or exchange transfusion).

\section{Analysis}

Descriptive analysis (proportions, means and standard deviations) was conducted to determine the frequencies of RBC alloantibodies and the associated neonatal outcomes.

\section{Results}

\section{Antibody Screening}

Over 10 years of study, 300 pregnant women had a positive antibody screen. Of these, 150 patients were determined to have 173 clinically significant RBC alloantibodies (Table 1). Forty-seven of these patients delivered at St. Michaels hospital resulting in 53 babies (5 patients had multiple pregnancies, 1 patient had twins), 31 of whom were considered at risk for HDFN.

The most common alloantibodies from the 173 were Anti-E (32\%), Anti-c (14\%), and Anti- Jk ${ }^{\mathrm{a}}(12 \%)$. Rh antibodies (anti-E, c, D, C, e, G, f) accounted for the majority of the antibodies (68\%) (Table 1).

\section{Neonatal Outcomes}

Of the 31 neonates at risk for HDFN, 13 (42\%) neonates underwent phototherapy, 2 neonates received an exchange transfusion and phototherapy and 2 neonates received IVIG, exchange transfusion and phototherapy. Of the two neonates who underwent both exchange transfusion and phototherapy, one neonate was born to a mother with Anti-D titre of 512 and the other born to a mother with Anti-D titre of 64 . Of the two neonates who received all three interventions, one was born to a mother with both Anti-c and Anti-f antibodies. The other's mother had Anti-c, Anti-Cw and Anti-Wra antibodies with titres of 8,2 and 4 respectively. Further details of neonatal outcomes are presented in Table 2 .

\section{Discussion}

We found that the most common maternal antibodies in pregnancies at risk for HDFN are Rh antibodies, this is consistent with the literature ${ }^{8}$. Most neonates required no treatment however a small amount required invasive treatments, and the literature on neonatal outcomes are sparse.

Despite RhIG prophylaxis, $10 \%$ of Rh-negative women had developed anti-D antibodies. The reasons may include unrecognized pregnancy or pregnancy loss, noncompliance with the prophylaxis program or inadvertent exposure to Rh positive blood components ${ }^{9-11}$.

Both of the neonates that required intensive therapy were associated with multiple antibodies, including anti-c anti-f, anti - $\mathrm{Cw}$ and anti-Wra. Of note, the mother with anti-c and anti-f had an anti-c titre increase 
from less than 1 to 8 between 30 and 37 weeks of gestation, while anti-f titre could not be determined due to presence of anti-c.

Outcomes for neonates born to mothers with anti-D were similar to those with other antibodies. Surprisingly, none of the neonates in our series born to mothers with Anti-D had a hemoglobin level less than $120 \mathrm{~g} / \mathrm{dL}$. Anti-D is of particular interest because despite universal prophylaxis with RhIG of Rh-negative women in most high-income countries, this antibody still has a relatively high prevalence. Newborn caregivers should continue to be vigilant in all countries due to immigration patterns and availability of RhIG to pregnant women.

Our study is a single centre, retrospective, observational study, and is further limited by the loss of information when neonates were delivered at and/or transferred to other hospitals. Furthermore, we do not have longer-term clinical outcomes for any of these babies.

Anti-Kell antibodies are usually associated with severe HDFN, however interestingly no newborns had severe HDN. This is inconsistent with previous literature ${ }^{12}$ but maybe due to our small sample size and the lack of our ability to track the newborn post-delivery thoroughly.

We propose the formation of an online centralized secure database for hospitals, or addition of relevant data to our existing provincial system to improve data quality in future studies. Improved knowledge on the effects of specific antibodies would enable better care for at risk pregnancies.

It is important to educate the patients and health care providers alike on the significance maternal alloantibodies. While most antibodies form as a result of a previous pregnancy, the minority that result from $\mathrm{RBC}$ transfusion can be decreased by limiting unnecessary transfusions in females of child-bearing age and through measures such as routinely providing Kell negative RBC to young women. It is important to test the biological father to determine if the fetus is at risk. If the fetus is found to be at risk though paternal testing and/or non-invasive testing, this patient should be followed by a high-risk obstetrician throughout her pregnancy and neonate tested and closely monitored for jaundice and anemia.

\section{Author Contributions:}

JB and JS initiated the study and applied for REB approval. JS collected the data with help from KP for the antibody data. All authors aided in the writing of the manuscript as well as reviewing the final manuscript.

\section{Acknowledgements:}

We would like to thank Russel Ombao, Monique Anderson and Elizabeth Krok for their assistance with the data that was retrieved from the medical laboratory.

\section{References:}

1. Zwingerman R, Jain V, Hannon J, Zwingerman N, Clarke G. Alloimmune Red Blood Cell Antibodies: Prevalence and Pathogenicity in a Canadian Prenatal Population. Journal of obstetrics and gynaecology Canada : JOGC = Journal d'obstetrique et gynecologie du Canada : JOGC . Sep 2015;37(9):784-790. doi:10.1016/s1701-2163(15)30148-1

2. Smith HM, Shirey RS, Thoman SK, Jackson JB. Prevalence of clinically significant red blood cell alloantibodies in pregnant women at a large tertiary-care facility. Immunohematology . 2013;29(4):127-30.

3. Zipursky A, Paul VK. The global burden of Rh disease. Arch Dis Child Fetal Neonatal Ed . Mar 2011;96(2):F84-5. doi:10.1136/adc.2009.181172

4. Roberts IA. The changing face of haemolytic disease of the newborn.Early human development . Aug 2008;84(8):515-23. doi:10.1016/j.earlhumdev.2008.06.005

5. Arora S, Doda V, Maria A, Kotwal U, Goyal S. Maternal anti-M induced hemolytic disease of newborn followed by prolonged anemia in newborn twins. Asian J Transfus Sci . Jan-Jun 2015;9(1):98-101. doi:10.4103/0973-6247.150968 
6. Geaghan SMMD. Diagnostic Laboratory Technologies for the Fetus and Neonate with Isoimmunization. Seminars in Perinatology . 2011;35(3):148-154. doi:10.1053/j.semperi.2011.02.009

7. Santiago JC, Ramos-Corpas D, Oyonarte S, Montoya F. Current clinical management of anti-Kell alloimmunization in pregnancy. European Journal of Obstetrics $\&$ Gynecology and Reproductive Biology . 2007;136(2):151-154. doi:10.1016/j.ejogrb.2007.03.003

8. Dean LMD, National Center for Biotechnology I. Blood groups and red cell antigens. NCBI; 2005.

9. Liumbruno GM, D'Alessandro A, Rea F, et al. The role of antenatal immunoprophylaxis in the prevention of maternal-foetal anti-Rh(D) alloimmunisation. Blood transfusion = Trasfusione del sangue . 2010;8(1):816. doi:10.2450/2009.0108-09

10. MacKenzie IZ, Findlay J, Thompson K, Roseman F. Compliance with routine antenatal rhesus D prophylaxis and the impact on sensitisations: observations over 14 years. BJOG : an international journal of obstetrics and gynaecology. Jul 2006;113(7):839-43. doi:10.1111/j.1471-0528.2006.00988.x

11. Baker JM, Campbell DM, Pavenski K, et al. Infants affected by Rh sensitization: A 2-year Canadian National Surveillance Study.Paediatrics \&3 Child Health . 2020;26(3):159-165. doi:10.1093/pch/pxaa025

12. Slootweg YM, Lindenburg IT, Koelewijn JM, Van Kamp IL, Oepkes D, De Haas M. Predicting antiKell-mediated hemolytic disease of the fetus and newborn: diagnostic accuracy of laboratory management. American Journal of Obstetrics and Gynecology . 2018;219(4):393.e1-393.e8. doi:10.1016/j.ajog.2018.07.020

\section{Hosted file}

Table 1.docx available at https://authorea.com/users/453400/articles/551231-neonataloutcomes-of-maternal-alloimmunization-to-red-blood-cell-antigens

\section{Hosted file}

Table 2.docx available at https://authorea.com/users/453400/articles/551231-neonataloutcomes-of-maternal-alloimmunization-to-red-blood-cell-antigens 